\title{
A randomised double-blind trial of diltiazem in the treatment of Raynaud's phenomenon*
}

\author{
ANDRE KAHAN, BERNARD AMOR, AND CHARLES J MENKES \\ From the Department of Rheumatology, René Descartes University, Hôpital Cochin, School of Medicinẹ, \\ Paris
}

SUMMARY The efficacy of diltiazem in the treatment of Raynaud's phenomenon was assessed i⿳⺈⿴囗十 a prospective double-blind randomised cross-over trial in 16 patients (7 progressive systemic sclerosis, 2 rheumatoid arthritis, 1 systemic lupus erythematosus, and 6 idiopathic Raynaud's phenomenon). Each patient received diltiazem $120 \mathrm{mg}$ and placebo three times a day for tw@ weeks. The attack frequency of Raynaud's phenomenon was measured by a diary count; it $\underline{\underline{s}}$. severity was assessed by means of a $10 \mathrm{~cm}$ visual analogue scale with 0 representing minimum and 10 representing maximum severity. Diltiazem significantly decreased the frequency and severit of Raynaud's phenomenon as compared with placebo. This improvement was striking in patient with idiopathic Raynaud's phenomenon but did not reach statistical significance in patients with associated systemic disease. We conclude that diltiazem is effective in the treatment of Raynaud'\& phenomenon, especially in patients with idiopathic vasospastic disease.

Key words: diltiazem, calcium channel blockers, Raynaud's phenomenon.

Raynaud's phenomenon may cause severe digital pain and functional disability, particularly in patients with underlying connective tissue disease. Trophic changes and fingertip ulcerations may develop in severe cases. The treatment of this condition is difficult. ${ }^{1-3} \mathrm{We}^{45}$ and others ${ }^{6-8}$ have shown that the calcium-channel blocking agent nifedipine is effective in the treatment of Raynaud's phenomenon. The calcium-channel blocker diltiazem causes vascular smooth-muscle relaxation and relief of coronary artery spasm..$^{9-12}$ Diltiazeminduced vasodilation has been shown to result in an increase in peripheral blood flow. ${ }^{10}$ Diltiazem has been used to treat idiopathic Raynaud's phenomenon $^{13}$ and patients with vibration disease. ${ }^{14}$ We conducted a prospective, randomised, controlled, double-blind, cross-over trial to assess the effectiveness of diltiazem in the treatment of Raynaud's phenomenon in patients with underlying connective tissue disease and of idio-

\footnotetext{
* Presented in part at the 56th Scientific Sessions of the American Heart Association, Anaheim, California, November 1983.

Accepted for publication 5 July 1984.

Correspondence to André Kahan, MD, Service de Rhumatologie, Hôpital Cochin, 27 rue du Faubourg Saint Jacques, 75014 Paris, France.
}

pathic Raynaud's phenomenon. Our results indicat that diltiazem is effective in some patients, partict larly in patients who have idiopathic Raynaud's phenomenon.

\section{Patients and methods}

Sixteen patients (14 women and 2 men) were selected on the basis of symptomatic bilaterif Raynaud's phenomenon. Their ages ranged from $1:$ to 57 years, mean 41.5 years. Seven patients had systemic sclerosis, two had rheumatoid arthritis, one had systemic lupus erythematosus, and six hace idiopathic Raynaud's phenomenon. The diagnoses of systemic sclerosis, rheumatoid arthritis ane systemic lupus erythematosus were based ong accepted criteria. ${ }^{15-18}$ Four of the seven patient with systemic sclerosis had a history of digital ulcers The mean duration of Raynaud's symptoms was 12.8 years, range 2 to 33 years. The study was cork ducted from October to April, when a cold ambierie temperature was likely. During the study period no patient was taking other vasoactive medication

After we had obtained their informed consen $\overrightarrow{\mathbb{B}}$ patients were entered into a prospective study with $\frac{}{\mathrm{T}}$ randomised double-blind cross-over protocol. Each patient received placebo three times daily in 
single-blind fashion for one week. Patients were then randomly assigned to receive, in a double-blind manner, either diltiazem $120 \mathrm{mg}$ three times daily for two weeks or placebo three times daily for two weeks, followed by a cross-over for the final two weeks.

During each period of the trial patients kept a record of their digital vasospastic attacks. Standardised diaries were provided for this purpose. The frequency of attacks was determined from the diary kept by the patient. The severity of Raynaud's phenomenon was assessed by means of a $10 \mathrm{~cm}$ visual analogue scale with 0 representing minimum and 10 representing maximum severity. At the end of each period of the trial patients were asked to evaluate subjectively the overall effectiveness of the study agents (marked or moderate improvement, no change, or worse).

The dependent variables measured in this study were frequency of vasospastic attacks, severity of Raynaud's phenomenon, and patient evaluation of the effectiveness of the study agent. The dependent variables to be measured were selected before the study was begun and were quantified before the drug code was broken. After completion of the analysis for all patients, subgroup analyses were performed. Patients were divided into two groups according to diagnosis: idiopathic Raynaud's phenomenon and Raynaud's phenomenon with systemic disease.

Statistical analysis. Differences in frequency and severity for the placebo and diltiazem periods of the study were analysed by means of Snedecor's F test. Differences in patient evaluation of the effectiveness of the study agent were analysed by means of Fisher's exact test.

\section{Results}

The results are shown in Table 1. Diltiazem significantly reduced the frequency and severity of Raynaud's phenomenon in the whole group as compared with placebo. There was no order effect for either frequency or severity of Raynaud's phenomenon.

In the six patients with idiopathic Raynaud's phenomenon diltiazem significantly decreased the frequency and severity of attacks. In contrast, in the 10 patients with associated systemic disease (progressive systemic sclerosis, rheumatoid arthritis, and systemic lupus erythematosus), the reduction in frequency and severity of Raynaud's phenomenon did not reach statistical significance.

Marked or moderate improvement was reported by 9 of the 16 patients ( 4 idiopathic Raynaud's
Table 1 Effect of diltiazem on the frequency and severity of Raynaud's phenomenon

\begin{tabular}{lrrrl}
\hline & $n$ & Placebo & Diltiazem & $P$ \\
\hline Frequency & & & & \\
All patients & 16 & $18 \cdot 9 \pm 4 \cdot 5$ & $12 \cdot 6 \pm 9 \cdot 5$ & $<0 \cdot 05$ \\
Idiopathic & 6 & $16 \cdot 3 \pm 2 \cdot 2$ & $8 \cdot 5 \pm 7 \cdot 8$ & $<0 \cdot 05$ \\
PSS + RA + SLE & 10 & $20 \cdot 4 \pm 4 \cdot 9$ & $15 \cdot 1 \pm 9.9$ & NS \\
Severity & & & & \\
All patients & 16 & $6 \cdot 2 \pm 1 \cdot 2$ & $4 \cdot 2 \pm 3 \cdot 2$ & $<0 \cdot 05$ \\
Idiopathic & 6 & $5 \cdot 4 \pm 0 \cdot 7$ & $2 \cdot 6 \pm 2 \cdot 8$ & $<0 \cdot 05$ \\
PSS + RA + SLE & 10 & $6 \cdot 6 \pm 1 \cdot 3$ & $5 \cdot 1 \pm 3 \cdot 2$ & NS \\
\hline
\end{tabular}

$\mathrm{n}$ : number of patients.

Frequency: number of attacks per two weeks.

Severity: the severity of Raynaud's phenomenon was assessed by means of a $10 \mathrm{~cm}$ visual analogue scale with 0 representing minimum severity and 10 representing maximum severity.

The results are shown as mean \pm standard deviation.

Statistical analysis: Snedecor's $F$ test.

NS: not significant

Idiopathic: patients with idiopathic Raynaud's phenomenon.

PSS + RA + SLE: patients with progressive systemic sclerosis, rheumatoid arthritis, and systemic lupus erythematosus.

phenomenon and five with systemic disease) while they were taking diltiazem, and by 3 of them ( 2 idiopathic and 1 with systemic disease) while they were taking placebo $(p=0 \cdot 029$, by Fisher's exact test).

The differences in the therapeutic effect of diltiazem between the group with idiopathic Raynaud's phenomenon and the group with systemic disease could not be explained by differences in the initial frequency or severity of vasospastic attacks, nor by differences in the mean duration of Raynaud's phenomenon $(13.8 \pm 11.0$ and $12 \cdot 2 \pm 10 \cdot 3$ years respectively), or the mean age $(35.8 \pm 9.1$ and $44.9 \pm 11.9$ years respectively).

The mean ambient temperature during the placebo and diltiazem periods of the study did not significantly differ.

At each visit inquiries were made about any side effects related to treatment. Side effects with diltiazem occurred in six patients: headache $(2$ -patients), flushing (2 patients), dizziness (1 patient), nausea ( 2 patients), and ankle oedema (1 patient). Side effects with diltiazem were generally mild and no patient discontinued the study because of side effects. The only side effects reported with placebo were transient light-headedness (1 patient) and nausea (1 patient).

\section{Discussion}

During diltiazem treatment some of our patients had a decrease in the frequency of attacks and a 
moderate or marked improvement in symptoms of Raynaud's phenomenon. However, the response to therapy varied.

In all 16 patients and in patients with idiopathic Raynaud's phenomenon diltiazem significantly reduced the frequency and severity of Raynaud's phenomenon. However, in patients with associated systemic disease the frequency and severity of Raynaud's phenomenon during the placebo and diltiazem periods of the study did not significantly differ. There may be several explanations for this failure to detect a significant improvement in patients with associated connective tissue disease. The apparently 'negative' results in this group may be explained by the small number of patients in our study ${ }^{19-21}$ The differences may have been due to variation in the pathophysiology of Raynaud's phenomenon. ${ }^{1222}$ A cause of Raynaud's phenomenon, particularly connective tissue diseases, can be identified in many patients referred to specialised clinics $;{ }^{22-24}$ symptomatic treatment with vasodilator drugs is most effective in those with the least vascular damage. ${ }^{22}$ Several arteriographic studies have demonstrated occlusive disease in the digital arteries of patients with systemic sclerosis; ${ }^{22}{ }^{25}$ these patients have marked intimal thickening of the small arteries and arterioles. ${ }^{26}$ However, some patients with systemic sclerosis may have abnormal vasospasm, and this is independent of the presence of demonstrable occlusive disease. ${ }^{22}$ The roles of immune complexes, of blood hyperviscosity and of other humoral or local mechanisms, in the pathogenesis of this condition remain uncertain. ${ }^{2} 222728$

It has been stressed that calcium ion concentration in vascular smooth muscle is an important factor promoting vasoconstriction. ${ }^{29}$ Recent interest in calcium-channel blocking agents in the treatment of cardiovascular disorders has been considerable; diltiazem, nifedipine, and verapamil cause vascular smooth-muscle relaxation and relief of coronary artery spasm..$^{-12}$ Our study shows that diltiazem (120 $\mathrm{mg}$ three times daily) significantly reduces the frequency and severity of Raynaud's phenomenon as compared with the placebo period. In another controlled study diltiazem (60 mg three times daily) was found to be effective in idiopathic Raynaud's phenomenon. ${ }^{13}$ In an open trial the effectiveness of diltiazem ( $30 \mathrm{mg}$ three times daily) in the treatment of patients with vibration disease has been reported. ${ }^{14}$ Four independent double-blind controlled clinical trials have shown the effectiveness of nifedipine in the management of Raynaud's phenomenon. ${ }^{5-8}$ In contrast, in two randomised double-blind trials verapamil was not effective in the treatment of patients with Raynaud's phenomenon..$^{30} 31$ This lack of response may refle the less potent vasodilator effect of verapamil. $\overrightarrow{\overrightarrow{0}}$ In our study side effects with diltiazem were milơ These findings accord with those of other studies suggesting that diltiazem is generally we्fl tolerated. ${ }^{10}$ However, conduction disturbances hace been reported. ${ }^{10}$ Studies in animals have suggested $P_{9}$ potential teratogenic effect. ${ }^{32}$ Although no similor experience has been reported in man to date contraception should be recommended when dit tiazem is prescribed for women of child-bearing age्

In conclusion, diltiazem significantly reduces the frequency and severity of Raynaud's phenomenoā, especially in patients with idiopathic vasospast disease. Further study is needed to determine the dose-response relation, the efficacy of long-terif therapy, the predictors of clinical responsiveness, and mechanism of action of diltiazem in Raynauds phenomenon.

\section{References}

1 Coffman J D. Vasodilator drugs in peripheral vascular disease $N$ Engl J Med 1979; 300: 713-7.

2 Halperin J L, Coffman J D. Pathophysiology of Raynaug disease. Arch Intern Med 1979; 139: 89-92.

3 Anonymous editorial: Episodic digital vasospasm-the legacy $\Theta$ Maurice Raynaud. Lancet 1977; i: 1039-40.

4 Kahan A, Weber S, Amor B, et al. Nifedipine for Raynaues phenomenon. Lancet 1983; i: 131.

5 Kahan A, Weber S, Amor B, Saporta L, Hodara M, Degeorges M. Etude contrôlée de la nifédipine dans le traitement \&̊ phénomène de Raynaud. Rev Rhum Mal Osteoartic 1982; 9 : 337-43.

6 Smith C D, Mc Kendry R J R. Controlled trial of nifedipine the treatment of Raynaud's phenomenon. Lancet 1982; fif: 1299-301.

7 Rodeheffer R J, Rommer J A, Wigley F, Smith C R. Control唌 double-blind trial of nifedipine in the treatment of Raynauds's phenomenon. $N$ Engl J Med 1983; 308: 880-3.

8 Winston E L, Pariser K M, Miller K B, Salem D N, Creaġor M A. Nifedipine as a therapeutic modality for Raynaungs. phenomenon. Arthritis Rheum 1983; 26: 1177-80.

9 Antman E M, Stone P H, Muller J E, Braunwald E. Calciợn channel blocking agents in the treatment of cardiovascufar disorders. Part I: Basic and clinical electrophysiologic effects. Ann Intern Med 1980; 93: 875-85.

10 Stone P H, Antman E M, Muller J E, Braunwald E. Calci別 channel blocking agents in the treatment of cardiovascutar disorders. Part II: Hemodynamic effects and clinical applifations. Ann Intern Med 1980; 93: 886-904.

11 Henry P D. Comparative pharmacology of calcium antagonists: nifedipine, verapamil and diltiazem. Am J Cardiol 1980; 8 : 1047-58.

12 Braunwald E. Mechanism of action of calcium-chanriotblocking agents. $N$ Engl J Med 1982; 307: 1618-27.

13 Vayssairat M, Capron L, Fiessinger J N, Mathieu J F, Houset E. Calcium channel blockers and Raynaud's disease. Intern Med 1981; 95: 243.

14 Matoba T, Ogata M, Kuwahara H. Diltiazem and Raynaươs syndrome. Ann Intern Med 1982; 97: 455.

15 Subcommittee for Scleroderma Criteria of the Ameriçan Rheumatism Association Diagnostic and Therapeutic Critera Committee: Preliminary criteria for the classification $\mathbb{Q}_{f}$ systemic sclerosis (scleroderma). Arthritis Rheum 1980; 官: 581-90. 
16 Cohen A S, Reynolds W E, Franklin E C, et al. Preliminary criteria for the classification of systemic lupus erythematosus. Bull Rheum Dis 1971; 21: 643-8.

17 Bennett P H, Burch T A. New York Symposium on population studies in the rheumatic diseases: new diagnostic criteria. Bull Rheum Dis 1967; 17: 453-8.

$18 \mathrm{McEwen} \mathrm{C}$. The diagnosis and differential diagnosis of rheumatoid arthritis. In: Hollander J L, McCarty D J Jr, eds. Arthritis and allied conditions. 8th ed. Philadelphia: Lea and Febiger, 1972: 403-18.

19 Young M J, Bresnitz E A, Strom B L. Sample size nomograms for interpreting negative clinical studies. Ann Intern Med 1983 99: $248-51$.

20 Freiman J A, Chalmers T C, Smith H Jr, Kuebler R R. The importance of beta, the type II error and sample size in the design and interpretation of the randomized control trial Survey of 71 'negative' trials. $N$ Engl J Med 1978; 299: 690-4.

21 Glantz S A. Biostatistics: how to detect, correct and prevent errors in the medical literature. Circulation 1980; 61: 1-7.

22 Blunt R J, Porter J M. Raynaud syndrome. Semin Arthritis Rheum 1981; 10: 282-308.

23 Vayssairat $M$, Fiessinger $J$ N, Housset E. Phenomène de Raynaud: étude prospective de 100 cas. Nouv Presse Med 1979; 8: $2177-80$

24 Harper F E, Maricq H R, Turner R E, Lidman R W, LeRoy E C. A prospective study of Raynaud phenomenon and early connective tissue disease. Am J Med 1983; 72: 883-8.
25 Rösch J, Porter J M, Gralino B J. Cryodynamic hand angiography in the diagnosis and management of Raynaud's syndrome. Circulation 1977; 55: 807-14.

26 Rodnan G P, Myerowitz R L, Justh G O. Morphologic changes in the digital arteries of patients with progressive systemic sclerosis (scleroderma) and Raynaud phenomenon. Medicine (Baltimore) 1980; 59: 393-408.

27 Van der Meulen J, Wouda A A, Mandema E, The T H. Immune complexes in peripheral blood polymorphonuclear leucocytes of patients with Raynaud's phenomenon. Clin Exp Immunol 1979; 35: 62-6.

28 McGrath M A, Peek R, Penny R. Blood hyperviscosity with reduced skin blood flow in scleroderma. Ann Rheum Dis 1977; 36: $569-74$

29 Zelis R. Mechanisms of vasodilation. Am J Med 1983; 74 (suppl 27 June): 3-12.

30 Kinney E L, Nicholas G G, Gallo J, Pontoriero C, Zelis R. The treatment of severe Raynaud's phenomenon with verapamil. $J$ Clin Pharmacol 1982: 22: 74-6.

31 Seaman J, Lovy M, Mac Carter D, Steigerwald J. Verapamil in the treatment of secondary Raynaud's phenomenon. Arthritis Rheum 1983; 26 (suppl): S27 (abstract 109).

32 Ariyuki F. Effects of diltiazem hydrochloride on embryonic development: species differences in the susceptibility and stage specificity in mice, rats, and rabbits. Okajimas Fol Anat Jpn 1975; 52: 103-17. 